\title{
The Study of the Regulation of "Car-Renting Under Network” From The Perspective of Information Display Mechanism
}

\author{
Pei Shang, Jinjing $\mathrm{Li}^{*}$ \\ Beijing Jiao tong University \\ *Corresponding author: Jinjing Li, Associate professor, 15801205283@163.com
}

\begin{abstract}
Rapidly developed car-renting based on the network greatly changed the industry, which arises challenges to traditional taxi industry regulatory agencies. This article first analysis the similarities and differences of them from the perspective of information display mechanism. The paper points out that the car-renting under network creates information asymmetry between regulator and company while eliminating the information asymmetry between demand and supply. Based on principle-agent model in regulation theory, the paper concludes that the key to solve the regulatory problems is to realize information symmetry between regulator and company instead of regulating price and quantity directly. Through the study of car-renting under the principal-agent model, this paper draws a conclusion that the government should require the network company to disclose the relevant information to maximize government supervision benefit.
\end{abstract}

Key words: car-renting based on network; regulation; information display

\section{Introduction}

Car renting based on network is derived from the concept of Shared economy, is a special form of Shared economy. "Sharing economic", also known as "share of the economy". Car-renting based on modern information technology can realize real-time supply and demand information matching; make the shortest distance of time and space come true, greatly improving the efficiency. The information display mechanism of car-renting based on network can effectively solve the part of the problem of incomplete information. Thus, the regulation of taxi based on negative externality and information asymmetry is not completely suitable for network about cars. In traditional taxis, drivers and passengers were unable to get the relevant information in advance. But car-renting based on network also has caused problems which the market can’t deal with. Government may have no way to know or the cost to get information directly is too large to bear, resulting in more serious information asymmetry problem.

To solve this problem, this article following will first introduce principal-agent model, to prepare for the discussion below; the part three will be the information display of car-renting 
based on network, compared with the taxi industry. Then, we will study the government regulation efficiency under the condition of information asymmetry and symmetry and the influencing factors. Finally, in consideration of the government objectives, we will build the index system of sharing information about car-renting based on network.

\section{The model of principal-agent}

From the perspective of economics, principal-agent relationship refers to the market which often exists information asymmetry between the agent and the principal; the superiority is often tend to seek to maximize its own interests, regardless of the other party's interests. The objective function of the agent and the principal is inconsistent, information asymmetry and uncertainty will lead to improper allocation of resources, produce moral hazard and adverse selection, resulting market inefficiency. Principal-agent model is to emphasize the principal can use an indirect way to supervise the agents. According to Maurice and Holmes, the distribution function of parametric method, the government regulation model can be expressed as follows: If $\mathrm{M}$ is refers to the enterprise all choose a combination of action, $\mathrm{M}$ said enterprise of a particular action (which contains $\mathrm{M} \mathrm{M}$ ), c (M) to show the enterprise is the cost of the action. Theta refers to is not affected by the government and enterprises, exogenous random variable and its distribution function for $\mathrm{G}(\theta)$ (for its distribution function $\mathrm{f}(\mathrm{x}, \mathrm{m}, \mathrm{PI})))$; a and $\theta$ to observed results of $\mathrm{x}(\mathrm{m}, \theta)$ and a monetary income PI $(\mathrm{m}, \theta)$. The government needs to design an incentive contract $s(x)$, namely according to the observed results for enterprises to carry out a certain number of rewards and punishments. Assume that governments and businesses expected utility function respectively, v (PI - s (x)) and u (s) (x) $\mathrm{c}(\mathrm{m})$. Government regulators goal is through the choice of $\mathrm{m}$ and $\mathrm{s}(\mathrm{x})$ to realize the expected utility maximization, namely:

$$
\begin{aligned}
& \underset{m, s(x)}{\operatorname{Max}} \int_{-\infty}^{\infty} v(\pi-s(x)) f(x, \pi, m) d x \\
& \int_{-\infty}^{\infty} u(s(x)) f(x, \pi, a) d x-c(a) \geq \bar{u}, \forall a^{\prime} \in A \\
& \int_{-\infty}^{\infty} u(s(x)) f(x, \pi, m) d x-c(a) \geq \int_{-\infty}^{\infty} u(s(x)) f\left(x, \pi, m^{\prime}\right) d x-c\left(a^{\prime}\right)
\end{aligned}
$$

If they accept the government's regulation measures, the expected utility the enterprise gain must not be less than their maximum expected utility in the case of not accepting, namely enterprise participation constraint (IR); If they will be able to access the action of the government wanted, their expected utility is not less than the utility of whatever they choose, then enterprises will take the initiative to choose the action, namely enterprise incentive constraint (IC). Only when the two conditions are both met, the enterprises will have an incentive to comply with regulations of government. 


\section{Information display of the car-rented based network}

\subsection{The information display of the taxi}

Taxi is hired by passengers to carry passengers. Taxi service is highly decentralized in time and space, supply and demand information matching mechanism is the key in the process of taxi service. According to the match of supply and demand, here are three main types: sweep the street parade, telephone appointment, casing on live. Take "Sweep the street parade" as example, it refers to both sides get each other with intention directly. Due to unable to get information in advance, each other need to search and wait for the cost. In this case, the empty cost driver and passengers waiting cost is huge, impossible to implement real-time matching supply and demand information. It is because of this kind of information asymmetry between supply and demand, "Taking a taxi is difficult" coexist with high ratio of empty phenomenon, this also caused urban road resources enormous waste. At the same time, due to the price information and service quality can't get timely delivery. "A one-off game” between passengers and drivers could easily lead to "bad behaviors of drivers". Taxi service information mainly reflected later and information display mainly depends on the taxi company's disclosure; passengers and drivers are unable to obtain information on both sides

\subsection{The information display of the car-rented under the network}

Real-time information match, dynamic pricing mechanism and credit mechanism of car-renting information display is the main difference from taxi. Supply and demand matching is based on the Internet and precise GPS positioning, according to users' requirements; after open the APP, enter the destination information, passengers will be the first to get accurate estimated time of arrival, the estimated price and the driver's real name, even can view real-time vehicle route. Dynamic pricing mechanism is mainly based on passengers and drivers' behavior, two sides' affection with supply and demand. The process cycles, keeps balance. Credibility feedback mechanism mainly refers to passengers' opportunity to give drivers praise or complaints. Information such as availability of supply and demand information, the route and price, can be learned that both parties before a deal, namely in the transaction phase, information is completely transparent for both party. The driver and vehicle information is unknown to the public before the transaction, namely information displays incomplete.

\subsection{The comparison}

\subsubsection{The match between supply and demand, service availability, the route and price}

Taxi drivers are unable to get the passengers' demand information, and need take a certain searching cost. Unable to get taxi operation information in detail, the government of taxi industry universal practice the strict quantity and price control. Car-renting based on network not only reduces the search costs, but also offers the supply and demand information, forecast 
the corresponding route and rate, save bargaining cost, improve the transparency of the deal; trading information fully displays and is effective, governments regulation lose basis.

\subsubsection{The driver information, vehicle information, quality and safety}

In the process of quasi-public transport, service quality, consumer security and privacy protection has always been a need to consider. The government supervision in a taxi the number and access depends on random inspection or routine check, but that can't often solve the problem. The credibility of car-renting service feedback system and company's application software masters the information such as driver, vehicle and service quality. But this kind of information limited in the company. The government needs to strengthen the ability to obtain such information.

\subsubsection{The area discrimination}

The revenue model of taxi driver will lead to the phenomenon such as refuse, detours; taxi companies or regulators are hard to obtain relevant information or achieve real-time monitoring, resulting the phenomenon of resources waste and unfairness. Car-renting based on network will automatically hold the driver in different regions at different times of the service according to the shortest distance of time and space to allocate vehicles. The contrast of them is as shown in table 1.

Table 1 - Comparison

\begin{tabular}{|c|c|c|c|c|}
\hline Basic information & Display & Taxi Service & Car-renting & Submit \\
\hline price & \multirow{3}{*}{ prior } & \multirow{3}{*}{ unsure } & \multirow{3}{*}{ determination } & \multirow{3}{*}{ “quit” } \\
\hline drive route & & & & \\
\hline service availability & & & & \\
\hline accident compensation & \multirow{6}{*}{ post } & \multirow{5}{*}{ determination } & \multirow{5}{*}{ determination } & \multirow{5}{*}{ "reinforce" } \\
\hline driver information & & & & \\
\hline quality of service & & & & \\
\hline vehicle security & & & & \\
\hline car rejection & & & & \\
\hline distribution of the origin & & unsure & determination & “add” \\
\hline
\end{tabular}

\section{The construction of the sharing index system}

\subsection{The network management under principal-agent model}

According to the above introduction of "parametric method of distribution function", we make the following assumptions: a (on behalf of the network platform about car company to supervise the vehicles, drivers, and so on according to level of efforts); $\mathrm{A}$ (on behalf of the 
network platform about car company's comprehensive ability level);R(by the daily routine inspection and consumer complaints platform company found the number of illegal); $\theta$ (the exogenous uncertainty caused by the illegal cases); $\alpha$ (daily management of the proceeds of the fixed income platform company); $\pi_{0}$ (a certain period of PI controllers for platform company set the regulatory standards of performance); $\beta$ (coefficient of rewards and punishments for government to platform company); The car-renting based on network platform company is risk averse, with the characteristics of the absolute risk aversion utility function, the utility function as the negative exponential function:, which benefits for actual money, as the absolute risk aversion measures;

a. supervision and management of the network platform company about car seized on the number of illegal: $S=A a+R+\theta\left(\operatorname{Var}(S)=\theta^{2}\right), \quad S(\pi)=\alpha+\beta\left(\pi-\pi_{0}\right)$;

b. supervision and management of the network platform company about car brought about by the social total benefit of the monetary income: $\pi=t(A a+R+\theta)$;

c. government regulators give platform company incentive mechanism: $Z=\beta\left(\pi-\pi_{0}\right)$;

f. platform company cost: $C(a)=b a^{2} / 2$

g. If, as random income, for the utility function, then for certain equivalent income. According to Arrow's research to known risk cost: $\rho \operatorname{Var}[S(\pi)] / 2=\rho \beta^{2} t^{2} \sigma^{2} / 2$.

Platform company certainty equivalent income:

$W=\alpha+\beta t(A a+R)-\beta \pi_{0}-b a^{2} / 2-\rho b^{2} t^{2} \sigma^{2} / 2$

(1)car-renting based on network platform company certainty equivalent income is not less than the retention of income level $\bar{W}$, namely participation constraint IR;(2) net platform company about a car always select the most optimal level of efforts to maximize their own interests, which motivate constraints of IC. Thus, the optimum regulation model can be expressed as:

$$
\begin{aligned}
& \underset{a, \alpha, \beta}{\operatorname{Max} E V}=\underset{a, \alpha, \beta}{\operatorname{Max}}\left[(1-\beta) t(A a+R)-\alpha+\beta \pi_{0}\right] \\
& I R: \alpha+\beta t(A a+R)-\beta \pi_{0}-b a^{2} / 2-\rho b^{2} t^{2} \sigma^{2} / 2 \geq \bar{W}, \forall a^{\prime} \in \wedge \\
& I C: \alpha+\beta t(A a+R)-\beta \pi_{0}-b a^{2} / 2-\rho b^{2} t^{2} \sigma^{2} / 2 \geq \alpha+\beta t\left(A a^{\prime}+R\right)-\beta \pi_{0}-b a^{2} / 2-\rho b^{2} t^{2} \sigma^{2} / 2
\end{aligned}
$$

A. In the case of information symmetry, IR participation constraint was established Government regulators expected return:

$E V^{*}=\left(1-\beta^{*}\right) t\left(A a^{*}+R\right)-\alpha^{*}+\beta^{*} \pi_{0}=A^{4} t^{2} / 2 b\left(A^{2}+\rho b \sigma^{2}\right)+R t-\bar{W}<E V^{*}=A^{2} t^{2} / 2 b+R t-\bar{W}$

B. In the case of information asymmetry and incentive constraints of IC 
Government expected return:

$$
E V^{* *}=\left(1-\beta^{*}\right) t\left(A a^{* *}+R\right)-\alpha^{* *}+\beta^{* *} \pi_{0}<E V^{*}=A^{2} t^{2} / 2 b+R t-\bar{W}
$$

\subsection{The building of Information sharing Index system of car-renting based on network}

Information sharing index system, to solve information asymmetry problems between the government and the company, plays a main role in correcting market failure to create the good environment of fair competition for the market. Market cannot solve the problem of quality of public goods and services, so government need to improve the information sharing system for environment, economy to maximize the social welfare. In consideration of the goals of government regulation, company, driver and the interest of consumers, the article analyses various factors on the government regulation efficiency, and classify them from

Table 2 - Sharing index

\begin{tabular}{|c|c|c|c|c|c|c|}
\hline & factors & b & $\mathbf{t}$ & $\sigma^{2}$ & $\rho$ & Sharing information \\
\hline \multirow[t]{2}{*}{ discrimination } & start-off location & & $\sqrt{ }$ & $\sqrt{ }$ & & \multirow{2}{*}{$\begin{array}{l}\text { driver mileage report; } \\
\text { platform preferential subsidies }\end{array}$} \\
\hline & rejection rate & & $\sqrt{ }$ & $\sqrt{ }$ & & \\
\hline \multirow{3}{*}{$\begin{array}{l}\text { fair } \\
\text { competition }\end{array}$} & platform subsidies & $\sqrt{ }$ & $\sqrt{ }$ & & & \multirow{3}{*}{$\begin{array}{l}\text { driver mileage report; } \\
\text { registered driver of platform; }\end{array}$} \\
\hline & driver travel rate & $\sqrt{ }$ & $\sqrt{ }$ & $\sqrt{ }$ & & \\
\hline & drivers registered & $\sqrt{ }$ & & & & \\
\hline \multirow{4}{*}{$\begin{array}{l}\text { public } \\
\text { goods }\end{array}$} & rejection rate & & $\sqrt{ }$ & $\sqrt{ }$ & & \multirow{11}{*}{ driver service evaluation report; } \\
\hline & unit mileage charge & $\sqrt{ }$ & $\sqrt{ }$ & & & \\
\hline & trip mileage & $\sqrt{ }$ & & & & \\
\hline & rate of loading & $\sqrt{ }$ & $\sqrt{ }$ & & & \\
\hline \multirow{7}{*}{$\begin{array}{l}\text { consumer } \\
\text { safety } \\
\text { and } \\
\text { privacy } \\
\text { protection }\end{array}$} & insurance (driver) & & & $\sqrt{ }$ & & \\
\hline & insurance (company) & $\sqrt{ }$ & $\sqrt{ }$ & & $\sqrt{ }$ & \\
\hline & driver training & $\sqrt{ }$ & & & & \\
\hline & driver qualification & $\sqrt{ }$ & & & & \\
\hline & rewards/punishment & & & & & \\
\hline & vehicle check & $\sqrt{ }$ & & & & \\
\hline & complaint rate & & $\sqrt{ }$ & & & \\
\hline \multirow{2}{*}{$\begin{array}{l}\text { external } \\
\text { effect }\end{array}$} & exhaust emissions & & $\sqrt{ }$ & & & vehicle fuel report; \\
\hline & car quantity & $\sqrt{ }$ & & & & vehicle number during rush hour; \\
\hline \multicolumn{2}{|c|}{ government expected return: EV } & - & + & - & - & \\
\hline
\end{tabular}

market order, public goods and external effects. Finally, we could get the sharing index 
system as showed in Table 2.

From the comparative analysis of the expected return of government and platform company, we can see in the case of incomplete information, the principal regulator of expected return would be reduced; while with the aid of information disclosure by the platform company agent, the expected returns of government will increase. Specifically, the government's expected benefits will be subject to the parameters (b, t, $\sigma^{2}, \rho$ ), as shown. The above information sharing index building will help with the goal of maximum benefits of regulation.

\section{Conclusion}

The information display mechanism of car-renting based on network can effectively solve the problem of transaction information. The taxi regulation based on negative external effects and information asymmetry is not completely suitable for the car-renting based on network. The regulation measures and scope is necessary to make some adjustments. The government should not only support its development, but also strengthen the supervision of company. Especially, forcing the relevant information sharing index will be crucial to improve the efficiency of the government regulation.

\section{References}

1. J. Jenk, Theory meets practice in the taxi industry: Coase and UBER, MPRA, 2015(03).

2. P. S. Dempsey, Taxi Industry Regulation, Deregulation, and Regulation: The Paradox of Market Failure, SSRN, 1996.

3. M. W. Moszoro and P. T. Spiller, Coase and the transaction cost approach to regulation, SSRN, 2015(08).

4. A. Thierer, Christopher Koop man, Anne Hobson, and Chris Kuiper, How the Internet, the Sharing Economy, and Reputational Feedback Mechanisms Solve the "Lemons Problem”, SSRN,2015(05). 